Cuadernos de Relaciones Laborales

ISSN: 1131-8635

http://dx.doi.org/10.5209/CRLA.56766

\title{
Esperando al pacto por la educación
}

[en] Waiting for the Education Pact

Enrique Martín Criado ${ }^{1}$

\author{
ESTRAGÓN.- Vamos a ver. (Lleva a Vladimiro hacia el árbol y quedan \\ parados ante él. Silencio.) ¿Y si nos ahorcáramos? \\ VLADIMIRO.- ¿Con qué? \\ ESTRAGÓN.- ¿No tienes un trozo de cuerda? \\ VLADIMIRO.- No. \\ ESTRAGÓN.- Entonces no podemos. \\ VLADIMIRO.- Vámonos. \\ ESTRAGÓN.- Espera, tenemos mi cinturón. \\ VLADIMIRO.- Es demasiado corto. \\ ESTRAGÓN.- Tú me tiras de las piernas. \\ VLADIMIRO.- ¿Y quién tira de las mías? \\ Samuel Beckett, "Esperando a Godot".
}

Tras décadas de insistencia en que la mejor inversión era la educación, llegó la crisis y con ella importantes recortes en esa presunta inversión en capital humano. Recientemente el gobierno de España ha propuesto en varias ocasiones alcanzar un "pacto por la educación". Pero este pacto se está haciendo esperar, como hicieron esperar anteriores propuestas de pacto, como hace esperar Godot a Vladimiro y Estragón.

Margaret Archer (1979) nos muestra por qué es tan difícil alcanzar acuerdos sobre leyes educativas y por qué, una vez consensuadas, no suelen convencer a nadie. Desde que, con las leyes de escolarización obligatoria del siglo XIX, la totalidad de la población pasa por la escuela, todo el mundo se ve afectado por su funcionamiento: se establece una interdependencia fuerte entre el sistema escolar y el resto de la sociedad. Además, a medida que el sistema escolar se amplía, cada vez hay más grupos cuyo principal interés se halla en el sistema escolar: el cuerpo cada vez más amplio de profesionales de la enseñanza y de empresas relacionadas con ella. El sistema escolar se constituye así como un sistema multi-integrado: establece múltiples relaciones con una diversidad de grupos e instituciones y se convierte en punto de paso obligado para las estrategias de prácticamente el resto de la sociedad. Debido a ello, toda ley educativa moviliza a grupos, organizaciones, sectores con intereses muy diversos y, en la medida en que hay que lograr apoyos y acuerdos entre 
esta enorme diversidad de intereses, las leyes resultantes suelen dejar insatisfechos a todos ${ }^{2}$-lo que inicia un nuevo ciclo de reivindicaciones y llamadas a la reforma-. Por ello los sistemas escolares se caracterizan por su plurifuncionalidad subóptima: debido a que la política educativa es una mediación entre intereses divergentes, a que los proyectos políticos intervienen sobre sistemas ya conformados que funcionan según lógicas propias difíciles de modificar, a que su puesta en funcionamiento pone en juego las estrategias de docentes y otros grupos, el sistema escolar nunca se halla perfectamente adaptado al cumplimiento de los cometidos que se le asignan (Archer, 1979; Martín Criado, 2010).

Pero la dificultad de los pactos por la educación no se debe únicamente a la diversidad de intereses. Se debe también al hecho de que la educación es un bien posicional: el valor social de un título escolar depende básicamente de la cantidad de población que pueda acceder a él, esto es, del cierre social que asegure (Collins, 1989). Los títulos escolares abren puertas a quienes los poseen precisamente porque erigen muros para quienes carecen de ellos: los títulos escolares sirven para limitar la oferta de aspirantes a una determinada profesión en el mercado o a una determinada posición en las estructuras burocráticas -de ahí que su valor social dependa de su escasez-. Por ello, los intereses de los distintos grupos sociales en torno a la escuela no sólo son diversos: son opuestos. Si cada grupo quiere acceder al máximo de capital escolar posible, también está interesado en que ese capital escolar no se desvalorice, esto es, en que otros no puedan acceder a él.

La importancia del cierre social nos explica la aparente paradoja de que el éxito del sistema escolar en extender continuamente la escolarización de la población sea percibido por muchas capas sociales como el principal problema escolar. El caso español es aquí ejemplar: cada cohorte tiene más estudios que la precedente, cada cohorte es "la mejor preparada de la historia" (hasta la siguiente cohorte). Así, si en 1977 un $63 \%$ de la población de 25 a 29 años tenía sólo estudios primarios, en 2013 descienden al 7\%; a la inversa, los diplomados y licenciados universitarios pasan de un 8 a un 27\% (Martínez García, 2015). Ni siquiera la crisis ha parado este movimiento: así la tasa de matriculados en la universidad respecto al grupo de edad de 18 a 24 años pasó del 23,9\% en el curso 2005-06 al 29,7\% en 2014-15 (Martínez García, 2016).

Esta constante expansión escolar -que es un rasgo estructural de los sistemas escolares contemporáneos (Martín Criado, 2010)- no tiene como causa principal una mayor igualdad de los distintos estratos sociales ante el sistema escolar. Aunque la evidencia sobre la evolución de las desigualdades de acceso a los distintos tramos escolares es controvertida y no permite llegar a conclusiones claras (Fernández Mellizo-Soto, 2014), lo que sí está claro es que, aunque se hayan producido ligeras reducciones de la desigualdad en determinados momentos, persisten fuertes desigualdades escolares en función del origen social (Calero, 2006; Barañano y Finkel, 2014).

¿Cómo se explica que coexista una persistente desigualdad de oportunidades escolares con una constante expansión escolar? Por el efecto composición, como ha demostrado Carabaña (2013) en el caso del bachillerato: dado que en cada estrato social los hijos obtienen más estudios que los padres, a medida que se suceden las cohortes aumenta la proporción de población con mayores niveles de estudios y disminuye la de menor nivel. Este aumento se da en la población general y dentro de

Se puede ver esa diversidad de actores e intereses en el caso español en Bonal (2000) y Varela (2007). 
cada clase social: así, dentro del grupo ocupacional de "operarios", en 1987 sólo un $3,9 \%$ habían terminado estudios profesionales o universitarios; en 2011 el porcentaje había subido al 23,1\% (Martín Gimeno y Bruquetas Callejo, 2014; ver también Bonal, 2003).

Un pequeño ejemplo -inventado, pero no muy lejos de la realidad- puede servir para ilustrar este efecto composición. Supongamos tres niveles de estudios -primarios, secundarios y terciarios- y que las probabilidades de obtener un determinado título escolar son muy desiguales por origen social, según la siguiente tabla:

\begin{tabular}{|c|c|c|c|}
\hline Estudios de origen & \multicolumn{3}{|c|}{ Estudios de destino } \\
\hline & Primarios & Secundarios & Terciarios \\
\hline Primarios & 50 & 40 & 10 \\
\hline Secundarios & 10 & 50 & 40 \\
\hline Terciarios & -- & 20 & 80 \\
\hline
\end{tabular}

Supongamos que estas probabilidades se mantienen constantes y que en una generación tenemos una distribución de $50 \%$ de la población con estudios primarios, $40 \%$ con secundarios y $10 \%$ con terciarios. ¿Qué ocurriría al cabo de dos generaciones? Como muestra la siguiente tabla, sin necesidad de ningún cambio en la desigualdad de acceso a estudios terciarios, estos pasarían -en sólo dos generaciones- de representar un $10 \%$ a un $42,9 \%$ de la cohorte.

\begin{tabular}{|c|c|c|c|}
\hline & G1 & G2 & G3 \\
\hline Primarios & 5000 & 2900 & 1870 \\
\hline Secundarios & 4000 & 4200 & 3840 \\
\hline Terciarios & 1000 & 2900 & 4290 \\
\hline
\end{tabular}

Este aumento de la escolarización corre paralelo a la creciente importancia que han ido cobrando los títulos escolares en las estrategias de reproducción social de los distintos estratos sociales. Actualmente -y ya desde hace décadas- no son sólo las clases medias cultivadas las que centran sus estrategias de colocación de sus vástagos en la acumulación de capital escolar. El conjunto de las clases populares ha ido incrementando su apuesta escolar y actualmente intenta también conseguir los títulos escolares más altos posibles para sus vástagos (Martín Criado, 2006; Martín Criado y Gómez Bueno, 2017; Martín Gimeno y Bruquetas, 2014).

Esa enorme extensión de la escolaridad agudiza la competencia por los títulos escolares: al depender cada título de su escasez, su extensión lleva a prolongar más la escolaridad -desvalorizando aún más los títulos, en un círculo vicioso- o a buscar títulos más distintivos, menos accesibles.

El éxito del sistema escolar aumenta las tensiones en torno a él, al intensificar la competencia por los títulos en una situación donde la posición social, en los estratos sociales intermedios, depende cada vez más de la educación (Martínez Celorrio y Marín Saldo, 2012). Una tensión que agudizan tres cambios. En primer lugar, la aprobación de la L.O.G.S.E, que al instaurar la educación obligatoria -y comprensiva- hasta los 16 años aumenta la heterogeneidad social del alumnado de secundaria. En segundo lugar, la inmigración, que también incrementa la heterogeneidad social 
de los centros escolares de primaria y secundaria. Por último, la degradación del mercado de trabajo -descenso de salarios, empeoramiento de condiciones laborales, aumento del desempleo y de la precariedad- que amenaza las estrategias de reproducción social del conjunto de las clases medias y populares.

Estas evoluciones ponen a las clases medias al borde del ataque de nervios: los títulos escolares se convierten en condición necesaria pero no suficiente para la reproducción de sus posiciones sociales; aunque poseer títulos siga siendo un valor en el mercado de trabajo, el riesgo de sobre-cualificación es elevado ${ }^{3}$.

\section{Las estrategias de reproducción de las clases medias}

Ante estas evoluciones y la mayor tensión en el campo escolar, las clases medias refuerzan sus estrategias escolares para preservar a sus vástagos de todo posible desclasamiento por falta de los títulos escolares necesarios. Olmedo (2007) ha estudiado estas estrategias y, siguiendo la terminología de Bourdieu, distingue dos fracciones de las clases medias: las más ricas en capital cultural y las más ricas en capital económico. Aunque ambas fracciones utilicen todo tipo de tácticas para asegurar el máximo capital escolar posible para los hijos, se diferencian en la intensidad con que recurren a un tipo de prácticas u otro. Las fracciones más ricas en capital cultural recurren más a prácticas de parentalidad intensiva, las más ricas en capital económico recurren más a pagar para asegurar la escolaridad filial.

Se ve bien la diferencia entre ambas fracciones en la elección de centro. Las fracciones ricas en capital económico y con poco capital cultural son las que más recurren a centros privados y concertados (Fernández Esquinas y Pérez Yruela, 1999: 76). Las familias con títulos universitarios y menos capital económico, por el contrario, acuden algo más a centros públicos -aunque, debido a la subvención estatal a los concertados, también los utilizan con profusión, especialmente en los momentos de mayor riesgo de la trayectoria escolar (cursos previos a la prueba de selectividad, malas calificaciones, repeticiones de curso...)-.

Santa Cruz y Olmedo (2012) han estudiado las prácticas de las familias de clases medias que acuden a centros públicos. Esa elección va ligada a una movilización fuerte de energías y capital cultural parental para acompañar la escolaridad filial. Estas familias organizan el cotidiano familiar de acuerdo a las exigencias escolares. Además de vigilar de cerca la escolaridad filial y acompañar en los deberes, acuden a menudo al centro y participan activamente en el AMPA de la dirección del centro: ello les sirve para obtener información, contactos y para influir en las decisiones del centro o del profesorado. Al ver estos centros más arriesgados, participan mucho más para controlar su funcionamiento cotidiano. Asimismo, vigilan que sus hijos no se relacionen con pares de clase obrera. Por el contrario, aquellas familias que envían a sus hijos a centros privados o concertados sienten mucha menos necesidad

Aunque hay mucho debate en torno a la evolución de la relación entre empleos y títulos escolares -según las metodologías y los años considerados, la diferencia entre tener un título y no tenerlo aumenta o disminuye-, parece claro que los títulos escolares siguen teniendo un valor (es mejor tenerlos que no), pero también que existe un elevado riesgo de sobre-cualificación (Calero, 2006; Martínez Celorrio y Marín Saldo, 2012; Garrido Medina, 2012; Martínez García, 2015; Bonal, 2003, Fachelli y Planas, 2014). 
de vigilar de cerca lo que ocurre en la escuela: confían en que sea el centro quien controle y seleccione al alumnado (Olmedo y Santa Cruz, 2011).

El debate se ha centrado en la oposición centros públicos vs concertados y privados. De hecho, hay importantes diferencias: todas las investigaciones coinciden en la gran diferencia de estatus social entre el alumnado de los centros concertados y el de los públicos (a pesar de que según la legislación ambos deberían tener procedimientos similares de admisión del alumnado). Los centros concertados reclutan mucho más alumnado procedente de familias con ocupaciones más cualificadas, con más rentas y con mayor nivel educativo, y mucho menos alumnado inmigrante (Villarroya, 2000; Pérez-Díaz, Rodríguez y Sánchez Ferrer, 2001; Fernández Esquinas, 2004; Bonal, 2003; Escardíbul y Villaroya, 2009; Río Ruiz y Martín Gimeno, 2017). Esa diferencia se debe parcialmente a la ubicación de los centros -hay más concertados en las zonas de más estatus (Gómez Espino, 2017)- y a las estrategias de las familias: las de mayor estatus dedican muchos más esfuerzos y recursos en acceder a estos centros (Alegre Canosa y Benito Pérez, 2012). Pero también se debe a las propias estrategias de reclutamiento de los centros concertados: desde fijar cuotas por servicios "extraescolares" hasta prácticas selectivas no oficiales para alejar al alumnado de menor estatus (Villarroya, 2000; Bonal y Alabaigés, 2009; Calero, 2006). Estos mecanismos de selección, además, suelen operar porque, a pesar de que la legislación ofrece instrumentos legales para evitar la segregación, pocas veces los poderes públicos los utilizan -por el contrario, a menudo ceden a las presiones de los padres de clases medias, aumentando las ratios alumno/profesor en los centros concertados o autorizando la apertura de nuevas clases (Bonal, 2012)-.

Pero, como subraya Olmedo (2007: 208), la diferencia no es entre centros públicos y privados, sino entre centros de prestigio y el resto. De hecho, hay más segregación social dentro de la red pública que entre ésta y la concertada (Alegre, Benito y González, 2011; Bonal, 2012; Bonal y Alabaigés, 2009). Las familias de mayor estatus buscan colegios homogéneos socialmente (Olmedo y Santa Cruz, 2011): dedican grandes esfuerzos a evitar que sus vástagos acudan a aulas donde se mezclen con alumnado de orígenes sociales inferiores ${ }^{4}$. Estos esfuerzos pueden suponer una enorme dedicación de tiempo a indagar los mejores colegios -públicos o concertados- de la zona, pero también de movilización de redes sociales, utilización de capital social para avanzar en la lista e incluso trampas (Olmedo, 2007: 193-ss) -como falsos empadronamientos ${ }^{5}$.

Lo importante, por tanto, no es la titularidad del centro (público o privado), sino la composición social del alumnado: centros homogéneos de clases medias frente a centros que albergan porcentajes significativos de clases populares. Aunque ambas características han tendido últimamente a solaparse. Como subraya Fernández Enguita (2008), aunque el porcentaje de alumnado en la escuela privada y concertada se ha mantenido relativamente constante en los últimos años (en torno a un tercio del alumnado), su composición social ha ido variando: la escuela pública gana alumnado

Olmedo (2007: 216) señala que los padres "progresistas" suelen elegir centros públicos y criticar el elitismo de los concertados; sin embargo, hacen todo lo posible para que sus hijos acudan a colegios públicos prestigiosos. Ver, p. ej. "3000 padres sancionados por mentir para colar a sus hijos en el colegio preferido", laverdad.es, edición Murcia: http://www.laverdad.es/murcia/v/20100215/region/padres-sancionados-mentir-para-20100215. html 
de los estratos inferiores y lo pierde de los estratos superiores. Las clases medias huyen de aquellas escuelas públicas donde, a causa de la universalización de la secundaria comprensiva con la LOGSE ${ }^{6}$ y de la entrada de inmigrantes, ganan peso las clases populares (Calero, 2006; Bonal, 2015).

Las tácticas y decisiones en torno al centro son así un componente fundamental de las estrategias de las clases medias por asegurar o mejorar su posición relativa en la estructura de clases. A ellas se añaden múltiples estrategias fuera de la escuela para promover la escolaridad filial: organizar el ocio familiar para maximizar la acumulación filial de capital cultural, supeditar la organización doméstica a las exigencias escolares, contratar actividades extraescolares que aumenten el capital cultural filial, ayudar con los deberes o contratar clases particulares... Mención especial merece este último punto. Como mostramos Gómez Bueno y yo en el artículo que firmamos en este monográfico, la principal diferencia entre familias de clases populares y de clases medias no reside en la importancia que se le concede a la escolaridad filial, sino en los recursos disponibles para promoverla. Esta diferencia se ve de forma más clara en la ayuda con los deberes: mientras que las familias de clases medias tienen los medios culturales o económicos para ayudar a los hijos -directamente o contratando clases particulares-, las familias de clases populares carecen de ellos. Runte-Geidel (2013) constata que son un recurso utilizado por muchas familias -especialmente en secundaria- y que parece haber aumentado mucho en la década de 1990 -cuando se implantó la LOGSE- para estabilizarse en torno a un 62-65\% del alumnado de secundaria en la década de 2000.

\section{Las consecuencias de cierre social de las estrategias de las clases medias}

Las estrategias señaladas sirven a las clases medias para reproducir su posición social de padres a hijos: por ello se suele hablar, retomando la terminología de Bourdieu, de estrategias de reproducción. Pero también se pueden considerar como estrategias de cierre social. El uso de este término suele limitarse a aquellas prácticas que directamente buscan excluir a determinados grupos del acceso a ciertos recursos. Sin embargo, en la medida en que las acciones de los distintos actores y grupos sociales son interdependientes, las estrategias de colocación de los propios vástagos inevitablemente comportan desplazamiento de los vástagos ajenos.

Ello se ve bien en las consecuencias segregativas de la elección de centro por parte de las clases medias: al huir de determinados centros públicos, provocan que en éstos aumente la concentración de alumnos anti-escolares. Ello comporta cambios en la pedagogía de los profesores, en las expectativas que mantienen frente al grupo, en la interacción de los alumnos con los compañeros, perjudicando las oportunidades escolares del alumnado que queda en ellos -y reforzando a su vez, en un círculo vicioso, la huida de las familias con más recursos para promover la escolaridad de sus vástagos- (Alegre y Benito, 2012). Así, las estrategias de las familias de clases medias han terminado provocando que una reforma, como la LOGSE, que perseguía

\footnotetext{
Así, la escuela concertada y privada ha crecido entre 1990-2010 mucho más en la ESO que en primaria (Fernández Llera y Muñiz Pérez, 2012). Olmedo y Santa Cruz (2011) señalan que muchos padres utilizan estrategias mixtas, mandando a los hijos al sector público en primaria y al privado o concertado en secundaria. Ello provoca que la segregación por estatus social sea mayor en secundaria (Fernández Esquinas, 2004)
} 
una mayor equidad en el acceso a la educación secundaria, termine provocando una mayor desigualdad entre redes escolares (Valiente González, 2008).

Asimismo, los padres de clase media que acuden a centros públicos con mezcla social -a menudo por no tener otra alternativa, como cuando residen en municipios rurales con poca opción de elegir centro-, pueden presionar para que se constituyan agrupamientos de los alumnos por nivel escolar -y social-, a lo que muchos directores de centro acceden para evitar perder estos públicos y que se degrade la imagen del centro. Estas agrupaciones por rendimiento, como han demostrado numerosas investigaciones, son enormemente perjudiciales para el alumnado asignado a los grupos de nivel bajo (Pàmies y Castejón, 2015).

La conjunción de estas estrategias genera un cierre social en cascada. Las familias de clases medias con más recursos escolarizan a sus vástagos en colegios privados, concertados y públicos con alumnado homogéno. El resto de familias de clases medias y las fracciones más estables de la clase obrera intentan acceder a colegios públicos sin alumnado de poblaciones marginales o inmigrantes; cuando no lo consiguen, promueven la separación por nivel de conocimiento, esto es, que la segregación se produzca en el interior del propio colegio. Por último tendríamos los colegios-escoba, que acogerían a los estratos más desposeídos. Esta jerarquización de centros y públicos permitiría además a las clases cultivadas presentarse como tolerantes, frente a los obreros "racistas" que intentarían evitar a los inmigrantes $^{7}$...

Las estrategias de cierre social de las clases medias continúan en la universidad. Aquí, frente a la "masificación", se acude a la prolongación de la escolaridad (másteres), pero también a diferenciar por tipo de universidad (las privadas se han expandido a gran ritmo en la última década) y de itinerario (como muestra el artículo de Troiano et al. en este monográfico). Todas estas estrategias, en su conjunción, sirven para mantener la distancia relativa, esto es, para perpetuar la desigualdad social en los títulos escolares. Se corresponden así estos movimientos con la tesis de la desigualdad efectivamente mantenida (Lucas, 2001): cuando disminuye la desigualdad entre clases en años de scolaridad, las diferencias se trasladan a los tipos de itinerarios o de centros. El acceso universalista a la E.S.O. ha exacerbado la desigualdad entre centros; el aumento de acceso a la universidad, la desigualdad entre universidades y tipos de estudios.

\section{Los discursos del cierre social}

Esta situación de inflación escolar y de recomposición-intensificación de las estrategias de reproducción y cierre social de las clases medias nos permite entender buena parte de los discursos y las políticas sobre educación. Comencemos por los primeros: podemos leer algunos de los discursos más difundidos sobre los "problemas de la educación" como jugadas de construcción de problemas sociales desde la perspectivas de las clases medias o de fracciones de las mismas.

En las investigaciones, publicaciones y debates públicos se suele problematizar la segregación de los inmigrantes, no la de clase social, mucho más amplia y que explica en gran parte la de los inmigrantes (Alegre y Benito, 2012). 
Mileurismo. Esto es especialmente claro con la construcción de un problema que expresaba directamente las ansiedades de las clases medias: el mileurismo. El término apareció el 21 de agosto de 2005 en una carta al director en El País: "El mileurista es aquel joven, de 25 a 34 años, licenciado, bien preparado, que habla idiomas, tiene posgrados, másteres y cursillos (...) lo malo es que no gana más de mil euros". El término se difundió con celeridad y en 2014 entró en el Diccionario de la Real Academia de la Lengua. No importa que, como ha mostrado Martínez García (2013: 95-98), las probabilidades de ser mileurista varíen con el género y el origen social: todas las clases medias se veían reflejadas en ese retrato de la mayor injusticia que podían concebir, el desclasamiento de la "generación más formada de la historia", condenada a la misma precariedad y a similares bajos salarios que buena parte de la clase obrera - cuya situación no causaba ningún escándalo, a menos que ganaran más que los licenciados-.

La escuela ha fracasado. Un segundo problema, omnipresente en las últimas décadas -y especialmente desde la implantación de la LOGSE- es el del fracaso del sistema escolar. Este discurso es tan viejo como la escolarización obligatoria: se suele enunciar como una queja sobre la bajada de nivel y se recrudece especialmente cuando algún nivel escolar se hace accesible a los estratos sociales hasta entonces excluidos de él (Baudelot y Establet, 1990). El discurso sobre la bajada de nivel suele ser, así, un discurso elitista semejante a la queja sobre la "masificación" -por ejemplo, de la universidad-: es la queja de quienes ven sus cotos reservados educativos invadidos por alumnado que, a su juicio, no debería estar ahí.

Si el discurso sobre el fracaso de la escuela y la bajada de nivel no es nuevo, sí lo es la forma de enunciarlo: ahora se puede fundamentar "científicamente" gracias a la publicación de los informes PISA. Unos pocos puntos de diferencia con la media de la OCDE sirven para desencadenar un coro de jeremiadas deplorando el lamentable estado de la educación en España. Martínez García (2005) ha mostrado que estos lamentos no tienen fundamento: la diferencia en puntos es muy pequeña; además, si tenemos en cuenta la diferencia entre el nivel de estudios de los padres del alumnado español y el de otros países de la OCDE (mucho más elevado), resulta que el sistema escolar español es más eficaz que la media 8 .

Poco importa que las pruebas sean endebles y controvertidas: el discurso sobre el fracaso de la escuela no desfallece. Ello se ha debido a una curiosa confluencia de intereses entre ciertos sectores de la pedagogía innovadora, por un lado, y el Partido Popular -junto a las fracciones de clases medias que lo apoyan, más ricas en capital económico que en capital cultural ${ }^{9}$ - y el grupo de presión de las escuelas privadas, por otro. Ambos grupos tenían "soluciones" que vender. Los pedagogos innovadores, sus "nuevas" técnicas pedagógicas. El PP y las escuelas de titularidad privada, la privatización de la educación -bajo el lema de la "calidad"- y una contrarreforma de la LOGSE que, respetando la obligatoriedad hasta los 16 años (esto es, respetando los intereses de la patronal de escuelas concer-

Viñao (2004: 123-126) también sostiene que los datos no confirman el descenso del nivel de conocimientos que se atribuye a la L.O.G.S.E., pero que ello no acalla las críticas. "Poco importa, asimismo, que los alumnos de la LOGSE no hubieran llegado todavía a la universidad cuando ya desde ella se mantenía, de un modo incontrovertible, que el descenso apreciado en el nivel de conocimientos se debía a la misma" (Viñao, 2004: 126). Carabaña (2015), por su parte, sostiene que las pruebas PISA no sirven para evaluar la eficacia de las escuelas, al medir competencias muy generales que sobrepasan lo aprendido en la escuela.

Ver http://politizen.info/quien-vota-al-pp/ 
tadas), estableciera segregaciones más fuertes. Y para vender una solución hace falta un problema: de ahí que ambos sectores se esfuercen en construir y propagar la imagen del fracaso de la escuela.

¿A qué se debe que la escuela funcione tan mal? Si hay consenso en diagnosticar la enfermedad, no lo hay en su etiología. Esta ha sido muy variada. Así, los más arduos defensores del "libre mercado" han apuntado al profesorado funcionario como agente patógeno -en lo que coinciden con los pedagogos innovadores, pues estos venden formas "innovadoras" de enseñar y para ello necesitan denostar las prácticas docentes más extendidas-. Pero los discursos más extendidos se han dirigido al alumnado y sus familias: a sus presuntos déficits.

Falta cultura del esfuerzo. Este discurso ha estado en la base de sucesivos informes del think tank del PP -la Fundación para el Análisis y los Estudios Sociales, FAES- y se halla en la base de algunos puntos de la reforma educativa del ministro Wert. Se corresponde perfectamente con una visión liberal individualista: cada uno es responsable de su destino. Y supone un diagnóstico fácilmente comprensible - "razonable", de "sentido común", como diría un famoso dirigente del PP- del fracaso escolar: no se esforzaron lo suficiente. Este diagnóstico corre paralelo al lamento por la baja dade nivel y a la crítica a la LOGSE: no aprenden porque no se esfuerzan y no se esfuerzan porque no se lo exigen; el sistema sería laxo. El problema-nuevamente falso $^{10}$ - supone una perfecta conjunción de la ideología liberal individualista con el ethos de las viejas clases medias -sus palabras fetiches son voluntad y esfuerzo- y con la crítica de la LOGSE. De ahí su éxito -paralelo al lamento por la falta de voluntad y de esfuerzo de los ninis ${ }^{11}$-, que servirá para legitimar la implantación de un sistema más selectivo, escolar y socialmente.

Falta tiempo de calidad. Un último diagnóstico, cada vez más extendido - especialmente entre las fracciones de las clases medias más ricas en capital escolar y más "progresistas"-, es el del tiempo de calidad: si el alumnado de clases populares tiene más fracaso escolar, la culpa es de las madres y de los padres que no le han dedicado "tiempo de calidad".

Este diagnóstico no es sino una nueva variante de un antiguo discurso profundamente sociocentrista ${ }^{12}$ : nuestros hijos (de clase media) tienen más éxito en la escuela porque los educamos bien y nos preocupamos por ellos; vuestros hijos (de clase obrera) fracasan porque no le dedicáis suficiente atención (es el famoso discurso de la dimisión parental ${ }^{13}$ ) o no sabéis educarlos. Si los hijos de universitarios triunfan más en la escuela es porque sus padres y madres pasan más "tiempo de calidad" con ellos y les ayudan a desarrollar sus capacidades cognitivas. Basta plantearse el negativo de

10 Martínez García (2009) muestra que es más difícil aprobar secundaria en España que en la mayoría de los países de la OCDE. Además, España es uno de los países de la OCDE con mayor tasa de repetición de curso.

11 El discurso sobre los ninis -que es en gran medida un discurso sobre quienes abandonan el sistema escolar y no tienen empleo, esto es, sobre el sector más desfavorecido de las clases populares- puede leerse como la imagen invertida del discurso sobre los mileuristas. Todo lo que en éste era positivo, en el nini es negativo: al esfuerzo sin recompensa del universitario desclasado se le contrapone la recompensa sin esfuerzo del desempleado sin estudios.

12 Combessie (1969) muestra cómo la literatura en torno a los estilos familiares de educación por clase social es profundamente sociocentrista: siempre las prácticas de las clases medias son las buenas y las de la clase obrera, las malas. Y los términos con que se denominan reflejan este sociocentrismo: lo que en la clase media puede ser una educación "exigente", en la clase obrera es "autoritarismo".

13 En el artículo que firmamos Gómez Bueno y yo en el presente monográfico intentamos demostrar la falsedad de esta acusación. 
este discurso para ver todo lo que implica: los vástagos de clases populares fracasan más en la escuela porque son más tontos -no desarrollaron sus capacidades cognitivas- y son más tontos porque sus padres y madres no se preocuparon por ellos.

La expresión "tiempo de calidad" se ha traspasado así del campo de las luchas de género al de la legitimación de las desigualdades sociales. Originalmente el término les servía a las madres trabajadoras, especialmente a aquellas con estudios, para defenderse de la acusación de ser mala madre por dedicar "poco tiempo" a sus hijos: le dedico poco tiempo, pero es un tiempo de calidad (frente al tiempo en grandes cantidades, pero sin calidad, de las madres amas de casa). Progresivamente ha ido adquiriendo un sentido de clase social: tiempo de calidad es el que dedican las madres (y ahora también los padres) de calidad, esto es, con un buen estatus social y con estudios universitarios ${ }^{14}$. De esta forma, el término sirve para legitimar las desigualdades escolares confortando el contumaz sociocentrismo de las clases cultivadas -somos mejores y criamos mejor a nuestros hijos, que son más inteligentes-. Al mismo tiempo, desplaza toda explicación de -e intervención sobre- la desigualdad social al ámbito familiar, responsabilizando a las familias de estratos sociales inferiores de su situación (Gillies, Edwards y Horsley, 2016).

\section{Una política para el cierre social}

Se han analizado las políticas educativas de los gobiernos del Partido Popular como políticas neoliberales (Saura, 2015) o como una fusión de políticas neoliberales y neoconservadoras, en la línea de los gobiernos de Margaret Thatcher en el Reino Unido (De Puelles, 2005). También se las puede ver como intentos de recomposición del cierre social en la educación secundaria y superior.

Históricamente, los estratos superiores han recurrido principalmente a dos estrategias para contener el avance educativo de los estratos inferiores: la imposición de pruebas de acceso para los niveles superiores; la segmentación de los estudios de un nivel determinado en itinerarios o ramas de valor social y escolar muy diferente (Martín Criado, 2010: 256-ss). Estas tácticas se hallan claramente en la Ley Orgánica para la Mejora de la Calidad Educativa (LOMCE), aprobada en 2013, que también afianza la privatización y segregación de la educación, al tiempo que el conjunto de la política educativa -especialmente con los recortes- refuerza la selección económica en los itinerarios académicos.

La primera estrategia -y la que ha originado más debates públicos- fue intentar multiplicar las pruebas de acceso -al final de la educación primaria, de la ESO y del bachillerato-, para contener la supuesta "baja de nivel" debida a la "falta de esfuer-

14 De hecho, los estudios que defienden la importancia del tiempo de calidad parecen proceder de una manera: deciden si una actividad es tiempo de calidad o no en función de qué grupos sociales la realicen más. Esto se puede ver claramente, por ejemplo, en el estudio de Marí-Klose et al. (2010). Allí se contrapone claramente leer cuentos a los niños (actividad donde destacan las familias universitarias) como máxima expresión del tiempo de calidad a prácticas "presencialistas" de las familias con menos estudios como ir a "visitar familiares" o "simplemente (sic) a hacer recados" (p. 74-75). Posteriormente, para demostrar que hay una relación inversa entre castigo físico y estimulación intelectual se toman como índices de estimulación intelectual las prácticas en que destacan más las madres universitarias dejando fuera otras -como comer y cenar junto a los niños- donde destacan más las madres con menos estudios (p. 107-111). Los ejemplos se podrían multiplicar en esta y otras investigaciones. 
zo". A ella se le han añadido otras medidas para dificultar el acceso a bachillerato y universidad: disminuir el número de asignaturas necesarias para repetir curso en ESO y bachillerato y establecer dos titulaciones al finalizar la ESO, certificado de estudios y graduados, con opciones muy distintas de itinerarios académicos posteriores (Viñao, 2016).

La segunda estrategia consiste en reforzar la segmentación horizontal de los estudios: tanto en itinerarios, como en tipo de centros. En secundaria, se acentúan las medidas anteriores de segregación de buenos y malos alumnos que habían ido atenuando la comprensividad que en principio establecía la LOGSE ${ }^{15}$. Para ello, se separa a los alumnos en itinerarios a edades más tempranas: se diferencia en $4^{\circ}$ de ESO un itinerario "académico" -que conduce al bachillerato- y uno "aplicado" -que conduce a Formación Profesional-, y se establece la posibilidad de acceder a una "formación profesional básica" en $2^{\circ}$ de ESO.

Asimismo, se acentúa la segregación entre centros, básicamente estableciendo varias medidas que benefician a la educación concertada -que, como vimos, concentra cada vez más al alumnado de clases medias-, en nombre del "derecho a la elección". Así, se incrementan las posibilidades de establecer más conciertos o de aumentar el alumnado en los centros concertados ya existentes.

A su vez, la crisis económica ha sido la ocasión perfecta para acometer una de las reformas más impopulares en el campo escolar: reducir el gasto público. Esta contracción -por parte de gobierno central y autonómicos, especialmente de partidos conservadores- ha afectado mayoritariamente a los servicios educativos que más utilizan las clases populares: reducción de los servicios educativos de refuerzo, menores plantillas de profesorado en los centros públicos, aumento de las ratios alumnos-profesor, reducción de becas, incremento de coste de la matrícula en formación profesional... El descenso de la inversión en educación pública acelera además la huida de las familias de clase media de los centros públicos, reforzando, al deteriorar la educación pública, los argumentos de los partidarios de la privatización.

Especialmente significativo ha sido el endurecimiento de las condiciones para poder acceder a becas universitarias: los requisitos son más exigentes a medida que las becas son más cuantiosas, esto es, que van dirigidas a familias con menos recursos. Además, los solicitantes ni siquiera saben ahora cuál será la cuantía a percibir, lo que dificulta enormemente los proyectos a futuro de los posibles becarios. Esta nueva situación, unida al incremento de tasas universitarias, ha dificultado enormemente la escolarización en la universidad de los estudiantes procedentes de familias con escasos recursos, obligándoles a refugiarse en las carreras más baratas o más fáciles de aprobar $^{16}$-es decir, las de menor cierre social, las que peores perspectivas de empleo tienen-, a hacer constantes cálculos de asignaturas y notas, a sacrificar estudiar lo que les interesa por estudiar lo que se permite aprobar o incluso a abandonar (Río-Ruiz, Jiménez-Rodrigo y Caro-Cabrera, 2015).

Todas estas medidas han ido, así, en el mismo sentido: intentar erigir diques contra la masificación, poniendo más obstáculos al acceso a los títulos más valiosos a los estratos sociales con menos recursos económicos y culturales. Y ahora se propone un "pacto". ¿Será un pacto entre las fracciones de las clases medias más ricas en capital económico y las fracciones más ricas en capital cultural? Quizás. Sigamos esperando.

15 Ver el artículo de Javier Rujas en el presente monográfico.

16 Ver el artículo de Troiano et al. en este monográfico. 
Esta es la situación que abordamos en el presente monográfico, compuesto de cuatro artículos.

En el primero, "Economía política de la educación en tiempos de austeridad: mecanismos de gestión de la crisis en la política educativa catalana", Xavier Bonal y Antoni Verger analizan las estrategias mediante las que el gobierno de CiU en Cataluña intentó imponer y legitimar unas políticas de recorte en educación desde que ganó las elecciones en 2010. Estos recortes afectaron mucho más al sector público que a la educación privada subvencionada, y se ensañaron preferentemente en los servicios destinados mayoritariamente a las clases populares.

Bonal y Verger, siguiendo una tipología de Jessop, identifican tres mecanismos que permiten la imposición de estas políticas. El primero es el de la variación, la emergencia de nuevas prácticas, legitimadas por supuestas necesidades insatisfechas. En un primer momento las políticas se legitimaron con tres estrategias discursivas: aludir a la inevitabilidad de los recortes; responsabilizar al "excesivo" gasto del gobierno anterior y culpar al gobierno español.

El segundo mecanismo es el de la selección: identificar problemas y posibles soluciones. La crisis fue la ocasión que la derecha aprovechó para impulsar una "modernización conservadora" al estilo de Margaret Thatcher, combinando liberalismo económico e intervención en los contenidos de la enseñanza. Esta modernización se justificó mediante unas narrativas legitimadoras. En un primer nivel discursivo -contextual- éstas insistieron en derivar responsabilidades al exterior -la Unión Europea y el gobierno español- y en achacarle al sistema público una ineficiencia que sólo podría superarse emulando al sector privado. En un segundo nivel, se seleccionó aquella evidencia -por ejemplo, ciertos resultados discutibles de las pruebas PISAque supuestamente legitimaban las nuevas medidas -descartando la contraria-.

El tercer mecanismo es el de la retención: las medidas y narrativas que se ponen en marcha para consolidar una política educativa y contrarrestar resistencias y críticas. Aquí identifican tres estrategias: a) intentar cooptar potenciales actores críticos, buscando aliar a docentes -mediante discursos apologéticos de su profesionalidad- y familias -haciéndolas corresponsables del proceso educativo-; b) hacer públicos únicamente aquellos datos de evaluación de la política educativa que interesen; c) lanzar multitud de pequeñas reformas para dar una imagen de constante activismo por mejorar la educación e intentar dejar en segundo plano las medidas más impopulares.

Según Bonal y Verger, aunque estas medidas y narrativas no han evitado críticas y resistencias, sí han tenido un relativo éxito, visible en el hecho de uno de los gobiernos que ha aplicado los recortes presupuestarios más duros en la democracia no se haya tenido que enfrentar a un movimiento de resistencia de gran amplitud -como una huelga general educativa-.

En el segundo artículo, "Evolución del acceso a la universidad y de la elección de titulación universitaria entre la población joven en Catalunya", Helena Troiano, Dani Torrents, Albert Sánchez-Gelabert y Lidia Daza investigan si ha habido cambios en la composición social de los estudiantes universitarios en Cataluña con la crisis y con las reformas que se han introducido en los últimos años en la universidad (eliminación de ciclos cortos, mayor exigencia de presencialidad, eliminación de cuotas de acceso reservadas desde el ciclo superior de F.P. e incremento de las tasas de matrícula). Los autores muestran que la crisis no supuso mayor desigualdad en las tasas de acceso a la universidad por origen social: todos los estratos sociales aumentaron su acceso en los primeros años de la crisis -quizás debido a la falta de alternativas 
laborales -, y lo frenaron con el aumento de las tasas universitarias. Pero esto es solo una parte de la historia: la segunda es el acceso a los estudios universitarios que pueden tener más rentabilidad social -que son los más selectivos-. Aquí sí constatan un aumento de la desigualdad. Por un lado, aumentó la desigualdad por origen social en el acceso a titulaciones de mayor coste económico: mientras en 2002 prácticamente no había diferencias, en 2014 el aumento de tasas había alejado a muchas familias de clases populares de los estudios más caros. Por otro lado, en cuanto a elección de carreras difíciles, también constatan una evolución: mientras se ha reducido la desigualdad de género -gracias fundamentalmente al mayor acceso a titulaciones difíciles de las hijas de universitarios con notas altas-, ha aumentado la disparidad entre las propias mujeres, tanto en términos de notas de acceso como de origen social.

En el artículo que firmamos Carmuca Gómez Bueno y Enrique Martín Criado, "El mito de la dimisión parental. Implicación familiar, desigualdad social y éxito escolar", abordamos la presunta falta de implicación parental de las familias de clases populares con datos de la Encuesta Social 2010 de Andalucía. Esta presunta falta de implicación sería, según algunas teorías, la responsable de la diferencia de rendimiento escolar. Para evaluarlo distinguimos tres tipos de prácticas parentales en función de los recursos necesarios para llevarlas a cabo y dos cohortes, de 12 y 16 años. Nuestros resultados indican que en ambas cohortes la diferencia básica por estratos sociales se da en las prácticas que precisan de más recursos culturales y/o económicos: ayudar con los deberes y contratar clases particulares. En la cohorte de 12 años, en el resto de prácticas -vigilancia cotidiana de la escolaridad, sanciones, relaciones con la escuela- no hay diferencias importantes por estratos sociales: a estas edades todos los estratos sociales se implican mucho en la escolaridad filial. Las diferencias aparecen a los 16 años, sobre todo en relaciones con la escuela y, en menor grado, con la vigilancia cotidiana de la escolaridad y las sanciones ligadas al bajo rendimiento. Estas diferencias se dan sobre todo cuando los hijos tienen trayectorias de fracaso escolar: dado que en estas familias hay una fuerte implicación a los 12 años, parece lógico concluir que la menor implicación parental a los 16 años sería una consecuencia de estas trayectorias, no una causa de ellas -al contrario de lo que suponen muchos estudios transversales que, predispuestos a culpabilizar a las familias de clases populares de los malos resultados filiales, nunca consideran que los comportamientos parentales dependen también de los filiales-. La consecuencia que deducimos de estos resultados es que el problema no es de falta de voluntad o de implicación de las familias de clases populares, sino de desigualdad de recursos culturales y económicos. Una política educativa de lucha contra la desigualdad no debería centrarse en intentar "moralizar" a las familias de clases populares para subsanar sus imaginarios déficits de voluntad, sino en suplir esa desigualdad de recursos -en vez de acentuarla con prácticas como la de externalizar a las familias parte del trabajo de instrucción mediante la imposición continua de deberes-.

Cierra el monográfico el artículo de Javier Rujas, "Dispositivos institucionales y gestión del fracaso escolar: las paradojas de la atención a la diversidad en la ESO". Rujas analiza uno de los principales modos de gestión del fracaso escolar en los institutos -las "medidas de la atención a la diversidad"- a partir de un trabajo etnográfico en un instituto de secundaria. El artículo muestra cómo en la asignación a estas medidas intervienen no sólo el rendimiento escolar, sino especialmente la "actitud": las medidas se dividen entre aquellas dirigidas a los que "quieren y no pueden" -"recuperables"- y los "disruptivos". A su vez, la asignación a estas medidas estigmatiza 
al conjunto del alumnado destinado a ellas, modulando las expectativas docentes $\mathrm{y}$, a la postre, reforzando su segregación en la asignación a "vías muertas".

Rujas nos explica cómo la estigmatización y segregación de este alumnado no es un resultado inscrito en un dispositivo (en el sentido foucaultiano). Para entenderlo es preciso comprender la tarea docente cotidiana en interacción con las categorías de entendimiento profesoral. Intentar enseñar a un alumnado con pocas disposiciones académicas -o incluso antiescolares- no es tarea fácil y enfrenta a los docentes a frustraciones y contradicciones. La separación de los alumnos "difíciles" entra en contradicción con la ideología inclusiva que la mayoría de docentes afirma defender. La defensa de la atención individualizada al alumnado con más dificultades de aprendizaje se contradice con la atención a la "mayoría" y con la necesidad de impartir los contenidos programados en el currículo. La misión oficial de estos programas -subsanar las dificultades de aprendizaje- desemboca finalmente en una práctica docente de "adaptación" - reduciendo las explicaciones teóricas y multiplicando los ejercicios simples- ante las dificultades de tener que enfrentarse a públicos reacios. Estas contradicciones y sus efectos perversos remitirían a la contradicción fundamental de intentar gestionar en recorridos homogéneos a públicos escolarmente muy heterogéneos: la comprensividad de la LOGSE llevaría, paradójicamente, a estas formas de segregación escolar eufemísticamente llamadas "atención a la diversidad".

\section{Bibliografía}

Alegre, M.A., Benito, R. y González, I. (2011). "Procesos de segregación y polarización escolar: La incidencia de las políticas de zonificación escolar”. Profesorado, 12 (2) (en línea) http://www.ugr.es/ recfpro/rev122ART5.pdf [consulta 17 de enero de 2017]

Alegre Canosa, M.A. y Benito Pérez, R. (2012) “¿En qué se fijan las familias a la hora de escoger la escuela de sus hijos? Factores de elección y descarte escolar en la ciudad de Barcelona". Profesorado, 16 (3): 59-79.

Archer, M. S. (1979). Social Origins of Educational Systems. Londres: Sage.

Barañano, M. y Finkel, L. (2014) "Transmisión intergeneracional y composición social de la población estudiantil universitaria española: cambios y continuidades". Revista de la Asociación de Sociología de la Educación. 7 (1): 42-60.

Baudelot, Ch. y Establet, R. (1990). El nivel educativo sube. Madrid: Morata.

Bonal, X. ( 2000). "Interest groups and the state in contemporary Spanish education policy". Journal of Education Policy. 15 (2): 201-216.

Bonal, X. (2003). "Una evaluación de la equidad del sistema educativo español”. Revista de Educación, 330: 59-82.

Bonal, X. (2012). "Education policy and school segregation of migrant students in Catalonia: the politics of non-decision-making". Journal of Education Policy. 27 (3): 401-421.

Bonal, X. (2015). “Crisis, educación y desigualdad: una cuestión de paradojas". Investigar em Educação. 3: 23-32.

Bonal, X. y Alabaigés, B. (2009). "La segregación escolar en Cataluña". Cuadernos de pedagogía. 387: 89-94.

Calero, J. (2006). La equidad en educación. Informe analítico del sistema educativo. Madrid: Ministerio de Educación y Ciencia.

Carabaña, J. (2013). "Crecimiento del bachillerato e igualdad desde los años ochenta". Revista de la Asociación de Sociología de la Educación. 6 (1): 6-31. 
Carabaña, J. (2015). La inutilidad de PISA para las escuelas. Madrid: Los Libros de la Catarata. Collins, R. (1989). La sociedad credencialista. Madrid: Akal.

Combessie, J.C. (1969). "Education et valeurs de classe dans la sociologie américaine". Revue française de sociologie. 10 (1) : 12-36.

De Puelles Benítez, M. (2005). "La influencia de la nueva derecha inglesa en la política educativa española (1996-2004)". Historia de la educación: Revista interuniversitaria. 24: 229-253.

Escardíbul, J.O. y Villarroya, A. (2009). "The inequalities in school choice in Spain in accordance to PISA data". Journal of Education Policy. 24 (6): 673-696.

Fachelli, S. y Planas, J. (2014). "Inserción profesional de los universitarios: de la expansión a la crisis". Revista Española de Sociología, 21: 69-98.

Fernández Enguita, M. (2008). "Escuela pública y privada en España: La segregación rampante". Revista de la Asociación de Sociología de la Educación. 1 (2): 42-69.

Fernández Esquinas, M. (2004). "Elección de escuela: efectos sociales y dilemas en el sistema educativo público en Andalucía”. Revista de Educación. 334: 377-390.

Fernández Esquinas, M. y Pérez Yruela, M. (1999). Las familias andaluzas ante la educación. Sevilla: Consejería de Educación y Ciencia de la Junta de Andalucía.

Fernández Llera, R. y Muñiz Pérez, M. (2012). "Colegios concertados y selección de escuela en España: un círculo vicioso". Presupuesto y gasto público. 67: 97-118.

Fernández Mellizo-Soto, M. (2014). "La evolución de la desigualdad de oportunidades educativas: una revisión sistemática de los análisis del caso español”. Revista Española de Investigaciones Sociológicas. 147: 107-117.

Garrido Medina, L. (2012). "Estudios y trabajo de los españoles en la crisis de empleo". Estudios de economía aplicada. 30(1): 3-30.

Gillies, V., Edwards, R. y Horsley, N. (2016). "Brave new brains: sociology, family and the politics of knowledge". The Sociological Review. 64 (2): 219-237.

Gómez Espino, J. M. (2017). “¿Por qué lo llaman “cercanía” cuando quieren decir “zonificación"? Una propuesta de aplicación de un criterio estricto de proximidad en el proceso de admisión en los centros educativos andaluces". Comunicación. II Conferencia Ibérica de Sociología de la Educación. Córdoba, 13-14 de julio.

Lucas, S. R. (2001). "Effectively Maintained Inequality: Education Transitions, Track Mobility, and Social Background Effects". American journal of sociology. 106 (6): 1642-1690.

Marí-Klose, P., Marí-Klose, M., Vaquera, E. y Argeseanu Cunningham, S. (2010). Infancia y futuro. Nuevas realidades, nuevos retos. Barcelona: Fundación La Caixa.

Martín Criado, E. (2006). “Toute la famille à l'école. Transformation des familles des classes populaires et de leur relation à l'institution scolaire". Regards sociologiques. 31: 1-16.

Martín Criado, E. (2010). La escuela sin funciones. Barcelona: Bellaterra.

Martín Criado, E. y Gómez Bueno, C. (2017). "Las expectativas parentales no explican el rendimiento escolar". Revista Española de Sociología. 26(1): 1-20.

Martín Gimeno, R. y Bruquetas Callejo, C. (2014). "La evolución de la importancia del capital escolar en la clase obrera". Revista de la Asociación de Sociología de la Educación. 7 (2): 373-394.

Martínez Celorrio, X. y Marín Saldo, A. (2012). "Educación y movilidad social en España”, en AA.VV., Informe España 2012. Madrid: Fundación Encuentro: 117-172.

Martínez García, J.S. (2005). Dos reflexiones sobre el sistema educativo español: el nivel educativo no cae y las clases sociales sí existen. El viejo topo, 213: 66-73.

Martínez García, J.S. (2009) "Fracaso escolar, PISA y la difícil ESO”. Revista de la Asociación de Sociología de la Educación. 2 (1): 56-85. 
Martínez García, J.S. (2013). Estructura social y desigualdad en España. Madrid: La Catarata.

Martínez García, J.S. (2015). "Educación, mercado de trabajo, juventud y ciclo económico". Panorama Social, 22: 93-109.

Martínez García, J.S. (2016). “A menor inversión en educación, mayor proporción de estudiantes", en Politikon (en línea) https://politikon.es/2016/02/16/a-menor-inversion-en-educacion-mayor-proporcion-de-estudiantes/ [consulta 25 de junio de 2017].

Olmedo, A. (2007). Las estrategias de elección de centro educativo en las familias de clase media. Estudio de la Incidencia Social en un Mercado Educativo Local. Granada: Editorial Universidad de Granada.

Olmedo Reinoso, A. y Santa Cruz Grau, E. (2011). "Las familias de clase media y elección de centro: el orden instrumental como condición necesaria pero no suficiente". Profesorado. Revista de currículum y formación del profesorado. 12 (2) (en línea) http://www.ugr.es/ local/recfpro/rev122ART7.pdf [consulta 12 de febrero de 2017]

Pàmies Rovira, J. y Castejón, A. (2015). "Distribuyendo oportunidades: El impacto de los agrupamientos escolares en la experiencia de los estudiantes". Revista de la Asociación de Sociología de la Educación. 8 (3): 335-348.

Pérez-Díaz, V., Rodríguez, J.C. y Sánchez Ferrer, L. (2001). La familia española ante la educación de sus hijos. Barcelona: Fundación La Caixa.

Río-Ruiz, M.A., Jiménez-Rodrigo, M.L. y Caro-Cabrera, M.Jj. (2015) “The shifting financial aid system in Spanish University: grant-recipients' experiences and strategies”. Critical Studies in Education. 56 (3): 332-350.

Río Ruiz, M.A. y Martín Gimeno, R (2017) "Desigualdades educativas en Andalucía” en AAVV, I Informe. Observatorio de Desigualdad de Andalucía. Observatorio de Desigualdad de Andalucía, pp. 133-161 (en línea) http://www.observatoriodesigualdadandalucia. org/sites/default/files/i_informe_oda_0.pdf [consultado el 13 de junio de 2017].

Runte-Geidel, A. (2013). "La incidencia de las clases particulares en España a través de los datos de PISA". Revista Española de Educación Comparada, 21: 249-284.

Santa Cruz, E. y Olmedo, A. (2012). "Sacando lo mejor de cada niño: La participación de las familias de clase media en el centro y en la educación de sus hijos". Profesorado. Revista de Currículum y Formación del Profesorado. 15(2): 251-270.

Saura, G. (2015). “Think tanks y educación. Neoliberalismo de FAES en la LOMCE”. Education Policy Analysis Archives/Archivos Analiticos de Politicas Educativas, 23 (107) (en línea) http://dx.doi.org/10.14507/epaa.v23.2106 [consulta 16 de diciembre de 2016].

Valiente González, O. (2008). “AA qué juega la concertada?: la segregación escolar del alumnado inmigrante en Cataluña (2001-06)". Profesorado: Revista de curriculum y formación del profesorado. 12 (2) (en línea) http://www.ugr.es/local/recfpro/rev122ART6.pdf [consulta 16 de diciembre de 2016].

Varela, J. (2007). Las reformas educativas a debate (1982-2006). Madrid: Morata.

Villarroya Planas, A. (2000). La financiación de los centros concertados. Madrid: Ministerio de Educación, Cultura y Deporte.

Viñao, A. (2004). Escuela para todos. Educación y modernidad en la España del siglo XX. Madrid: Marcial Pons.

Viñao, A. (2016). "La Ley Orgánica de Mejora de la Calidad Educativa (LOMCE): ¿una reforma más?”. Historia y Memoria de la Educación. 3: 137-170. 